\title{
Are California Sea Lions (Zalophus californianus) Sensitive to the Attentional State of their Caretakers?
}

\author{
Marie Penel ${ }^{1 *}$ and Fabienne Delfour ${ }^{2}$
}

\author{
${ }^{1}$ Université de Rennes \\ ${ }^{2}$ Parc Asterix \\ *Corresponding author (Email: marie-penel@orange.fr)
}

Citation - Penel, M., \& Delfour, F. (2014). Are California sea lions (Zalophus californianus) sensitive to the attentional state of their caretakers? Animal Behavior and Cognition, 1(4), 434-441. doi: 10.12966/abc.11.01.2014

\begin{abstract}
Human-animal relations appear in various contexts (homes, farms, zoos, aquatic parks, etc.) possibly favoring the emergence of the ability to understand heterospecific communication signals in several species. Studies show that dogs (Canis familiaris) have developed the ability to attribute attention to humans, reading their body, head and gaze cues. Horses (Equus caballus) and other species including African gray parrots (Psittacus erithacus) show this ability too. Here, we asked if California sea lions (Zalophus californianus) can discriminate the attentional state of their caretakers. Four sea lions were tested in three increasingly complex experiments requiring them to make a choice between an attentive versus an inattentive caretaker. The first test asked whether sea lions could attribute attention to a human facing them versus facing away. In the second test, the caretaker's head orientation towards the sea lion served as the attentional cue. In the final test, the inattentive caretaker wore dark sunglasses. The results were heterogeneous and showed a higher rate of success than failure in the test 1, but the opposite in test 2. The results in the test 3 were not significant. Furthermore, the latency measures suggested that the subjects did not understand the tasks. It therefore appears that in the situation used here sea lions mainly focused their attention on the experimenter's body orientation; the head did not seem to be a pertinent cue.
\end{abstract}

Keywords - Attention, Choice task, Gaze, Sea lions, Zalophus californianus

Primatologists Premack and Woodruff (1978) specified theory of mind as the ability to attribute mental state to oneself and others, i.e., thinking about a parameter which is not visible and also predicting the future acts of others. One such mental state is attention, as in paying attention to someone. A human child acquires the ability to attribute attention between 0 and 2 years old (Baron-Cohen, 1994). This development occurs in the context of the intraspecific relation between the child and people around him. The question arises whether similar phenomena occur within interspecific relations. Numerous human societies include nonhuman animals, and not only for food or protection; for example most of our dogs (Canis familiaris) and cats (Felis silvestris catus) are chosen for their companionship (Miklósi, Polgárdi, Topál, \& Csányi, 1998). Human-animal relations appear in various contexts: farms, zoos, aquatic parks, etc. These contexts could have favored the emergence of the ability to understand heterospecific communication signals in several species.

Humans have become social partners for dogs over time, and the latter have learned to discriminate various cues of human attention including body, facial and visual cues (Kaminski, Bräuer, Call, \& Tomasello, 2009; Riedel, Schumann, Kaminski, Call, \& Tomasello, 2008, as cited in Udell, Dorey, \& Wynne, 2010; Soproni, Miklósi, Topál, \& Csányi, 2001). Dogs are able to use these human cues to solve an object choice task, to localize or beg for food (Bräuer, Call, \& Tomasello, 2004; Gásci, 
Miklósi, Varga, Topál, \& Csányi, 2004; Miklósi et al., 1998; Soproni et al., 2001; Virányi, Topál, Gásci, Miklósi, \& Csányi, 2004). Some nonhuman primates, for example gorillas (Gorilla gorilla) have demonstrated this ability too: they used body cues, but also focused on a human's gaze to make their choice (Bania \& Stromberg, 2013). Orangutans (Pongo pygmaeus) understand human head cues (Tempelmann, Kaminski, \& Liebal, 2011), and cotton-top tamarins (Saguinus oedipus oedipus) use human body and gaze cues to discriminate human attention (Santos \& Hauser, 1999). Even some birds such as African gray parrots (Psittacus erithacus) can discriminate human gaze cues (with head orientation) (Giret, Miklósi, Kreutzer, \& Bovet, 2009) and are able to use them in the same choice task as primates do (Péron, Chardard, Nagle, \& Bovet, 2011). Bottlenose dolphins' (Tursiops truncatus) pointing and monitoring behaviors are linked to human receiver's attentional behavior (Xitco, Gory, \& Kuczaj, 2004). Horses are also able to discriminate human attention using body, head and gaze cues (Proops \& McComb, 2010). The horse "Clever Hans" could "solve" simple equations by discriminating various unintentional body cues sent by the audience, such as breathing, when the owner voiced numbers.

According to some authors (Buttelman, Carpenter, Call, \& Tomasello, 2007; Call, 2001; Kaminski, Riedel, Call, \& Tomasello, 2005; Kaminski et al., 2009), the ability to understand heterospecific communication signals could be due to the species enculturation or domestication. However, Udell, Dorey, \& Wynne (2011) demonstrated sensitivity to human attentional state in some non-domesticated animals. Nonetheless there is general agreement that proximity between animals and humans could have contributed to several species' ability to infer human mental states.

In some environments (e.g., zoos, farms, dolphinaria, etc.), animals live close to humans. California sea lions (Zalophus californianus) are commonly housed in zoos or amusement parks. These pinnipeds naturally live in the North Pacific and belong to the family Otariidae. They can weigh as much as $390 \mathrm{~kg}$ and can be up to $2.20 \mathrm{~m}$ tall. They are sexually dimorphic, with males being bigger than females, reach sexual maturity between 4 and 5 years of age, and live about 15 years. These animals congregate during the breeding season, forming large herds subdivided into harems, composed of one male and 3 to 40 females. Males defend their harem aggressively. Young animals stay close to their mother until they are at least 5 months old, learning to recognize them using smell, sight and vocalizations (Riedman, 1990). There have been studies of these animals' anatomical and functional characteristics (Schusterman, 1969; Wells, Irwin, \& Hepper, 2006) but few behavioral studies have been conducted, particularly regarding their interactions with humans.

In this study, we wanted to know if California sea lions (called "sea lions" here) understand human attentional signs, and which signs are pertinent for them. We conducted three experiments using three different attentional cues used in previous studies (Proops \& McComb, 2010). In the first test, one human was facing the subjects (attentive) while another was facing away (inattentive). In the second test, the human's head orientation towards the sea lion was the attentional cue. In the final test the inattentive caretaker wore opaque sunglasses.

\section{Method}

\section{Subjects}

The four California sea lions (Zalophus californianus) tested here all born and bred under human care. They were 4 males: Santo (7 years old), Smack (6), Gonzo (4) and Kaï (3), living at Parc Asterix Delphinarium (France). Their enclosure measured $12 \times 31 \mathrm{~m}$ with a $5 \times 15 \mathrm{~m}$ outdoor pool and a $3 \times 5 \mathrm{~m}$ indoor enclosure. They were fed with herring, mackerel, capelin and squid distributed in 6 daily rations including one given during a session without training or show. The sea lions were familiar with a range of communication signs used by their caretakers and were trained by each team member. The study took place during regular training sessions. 


\section{General procedure}

Three familiar caretakers participated in each trial: one caretaker (A) stood by the sea lion and gave him the command "to go to a person" which allows the sea lion to leave caretaker A and go to caretakers B or C who, about $2 \mathrm{~m}$ from each other, stood in front of the sea lion at a distance of $4 \mathrm{~m}$ (Figure 1). Following Proops and McComb's (2010) procedure, we started with a warm-up phase with two attentive caretakers to show their attentional state, caretakers B and C looked at the subject until caretaker A sent him to make his choice. After the subject was sent, caretakers B and C did not look at him as he moved to avoid influencing his response (except for experiment 3 ). The choice was considered made when the subject stood close to one of the caretakers. Only the attentive trainer gave a vocal and/or tactile reward; the inattentive experimenter did not move or look at the subject. Finally, the sea lion was called back by caretaker A. A then gave him a few commands and rewarded him with food. We used vocal rewards rather than food rewards in order to prevent sea lions learning to look for food instead of signs of attention. A Samsung ${ }^{\circledR}$ 65X Intelli-Zoom video camera was used to record the experiments and the videos were analyzed with Windows Live Movie Maker®.

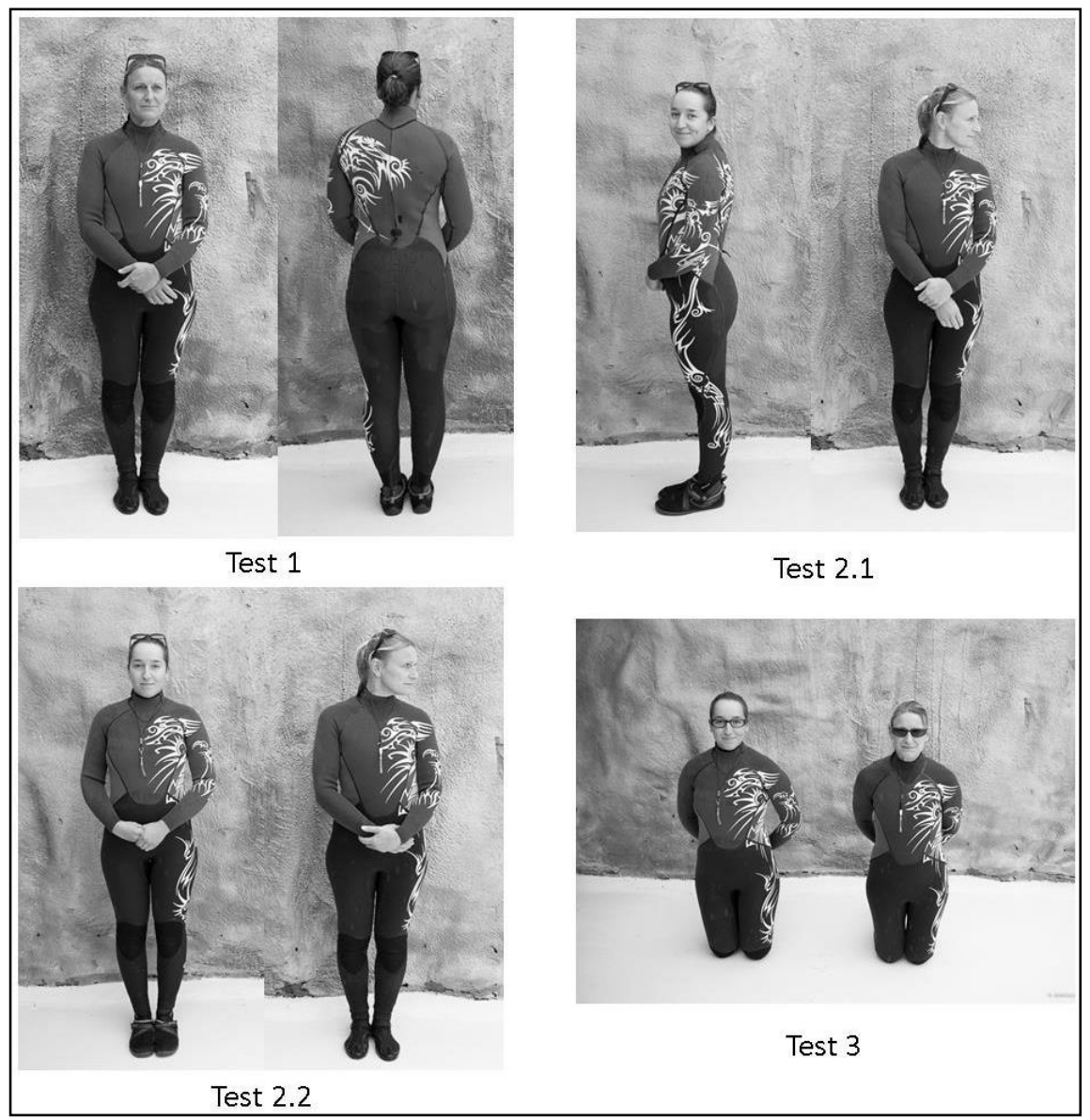

Figure 1. Pictures of the different postures used in this study. For each picture, the attentive caretaker is on the left. Picture 1 represents the body orientation, pictures 2.1 and 2.2, the head orientation and picture 3 , the eye visibility.

Shaping phase 1. During this phase the trainers desensitized the subjects to the new procedures. By facing and looking at the sea lion, caretakers B and C were both showing the "attentive state." First, the reward was only vocal and/or tactile to test different places in the enclosure and avoid bias (5 days) (e.g., confusion arising from the fact that the signs for "go to a person" and "go to the water" were similar). Then, caretakers B and C alternated positions and status (attentive vs. inattentive) and for 3 days 
they added food reward to their vocal/tactile reward. We did not want the sea lions to learn a route or a particular location. Finally, neither caretaker B nor C rewarded the subject with fish (2 days); only caretaker A did so. From this phase, the caretakers wore sunglasses on their head to habituate subjects for experiment 3. This phase lasted for 10 days and subjects received variable numbers of trials (Santo: 47; Smack: 38; Gonzo: 42 and Kaï: 36) depending on availability.

The statistical analysis of the choice of any of the three caretakers, or side (left/right) was nonsignificant for each sea lion (Binomial, $p>0.05$ ).

\section{Statistical analysis}

For each experiment and each subject, comparisons of the choice of the attentive / inattentive caretaker (Exp. 1, face forward vs. back turned; Exp. 2, face forward/body turned vs. face turned/body forward and face forward/body forward vs face turned/body forward; Exp. 3, eyes open vs. sunglasses) and the choice of caretakers and side (left/right) were analyzed with a binomial test. Latency (time between the subjects leaving caretaker $\mathrm{A}$ and choosing caretaker $\mathrm{B}$ or $\mathrm{C}$ ), and the duration of the behavior "looks at caretakers" before choosing were analyzed using the Mann-Whitney-U test. Inter-individual variation and daily patterns of response rates were analyzed using Chi Square tests, but for all experiments, they were non-significant, and there was no bias for any subject selecting a specific caretaker $(p>0.05)$.

\section{Experiment 1: Body Orientation}

\section{Face forward vs. back turned}

Procedure. During this test, two caretakers were in front of the subject with one of them looking forward ("attentive state") and the other with his/her back facing the subject (inattentive state). Each subject received 42 trials.

Results. The four sea lions successfully passed the first test (Test 1$)(N=168, \mathrm{k}=121, p<0.01$; Santo: $N=42, \mathrm{k}=28, p<0.05$; Gonzo: $N=42, \mathrm{k}=29, p<0.05$; and Kaï: $N=42, \mathrm{k}=30, p<0.05$; Smack: $N=42, \mathrm{k}=34, p<0.01$ ) (Figure 2). They also looked significantly longer at the attentive caretaker than the inattentive one before choosing ( $\mathrm{W}=16926.5, p<0.001)$.

However, the sea lions did not choose the attentive caretaker faster than the inattentive one $(p>$ 0.05 ) except for Smack, who took longer to go to the attentive caretaker (Table 1) (W=51.5, $p<0.02)$.

Finally, three sea lions preferentially chose a particular side: left for Santo $(N=42, \mathrm{k}=32, p<$ $0.001)$ and Kaï $(N=42, \mathrm{k}=28, p<0.05)$, right for Gonzo $(N=42, \mathrm{k}=31, p<0.01)$.

\section{Experiment 2: Head Orientation}

\section{Part 1: Face forward/body turned vs. face turned/body forward}

The attentive caretaker turned her head to face the sea lion with her body turned $90^{\circ}$ (always facing away from the inattentive caretaker). The inattentive caretaker had her body facing the sea lion but her head turned away (not towards the attentive caretaker). Each subject made 42 trials. 


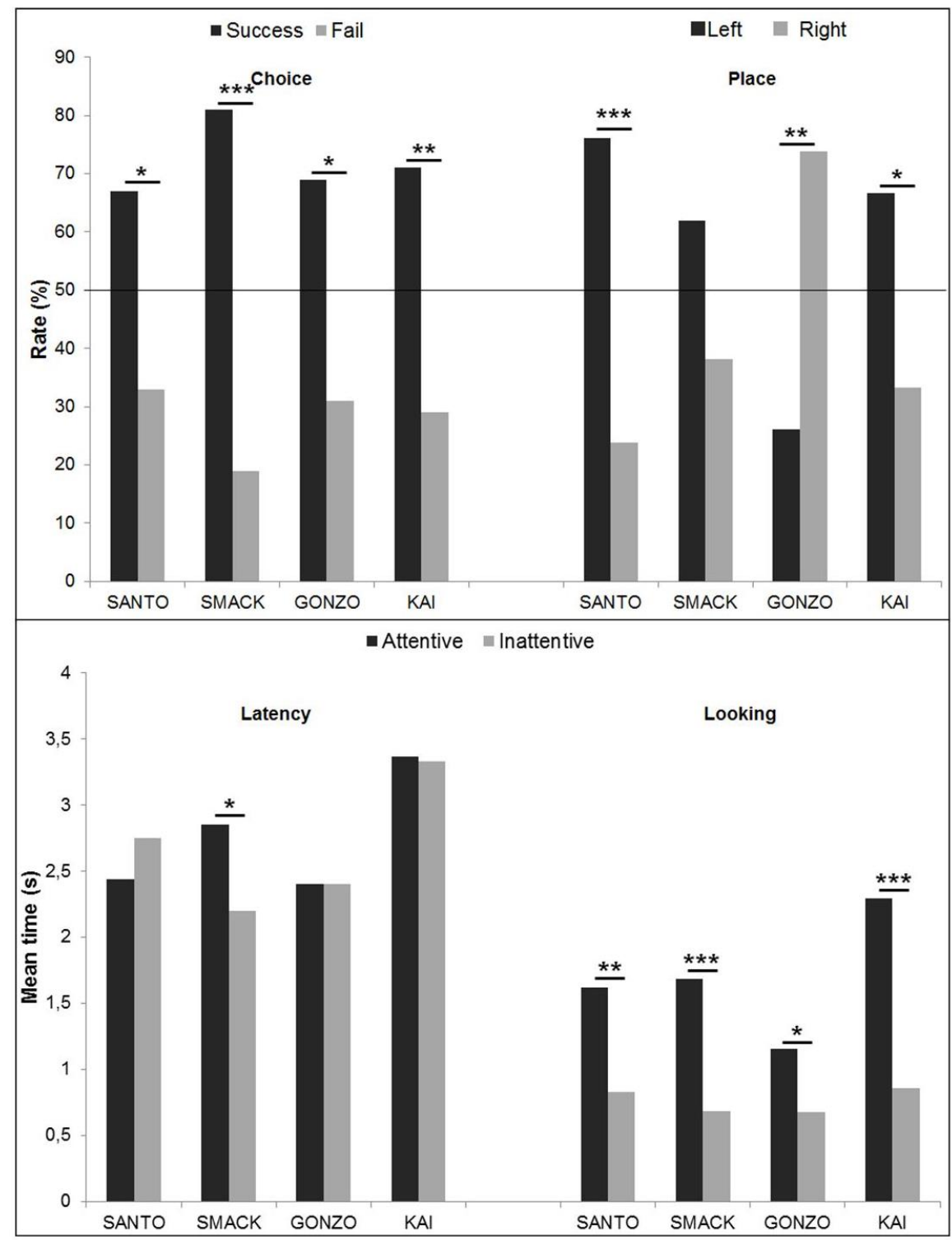

Figure 2. Test 1: body orientation. For each sea lion, Success / Failure rate and place (top) and mean time (s) of the response time (latency) and duration (s) of looking at the caretakers (down) during experiment 1 . The line shows the random level with $50 \%$. $*=\mathrm{p}<0.05 ; * *=\mathrm{p}<0.01 ; * * *=\mathrm{p}<0.001$

Results. The 4 sea lions failed this test $(N=168, \mathrm{k}=102, p<0.01)$, and they did not preferentially look at the attentive caretaker vs. the inattentive one before choosing (Santo: $\mathrm{W}=753.5, p$ $=0.23$; Smack: $\mathrm{W}=672.5, p=0.21$; Gonzo: $\mathrm{W}=834.5, p=0.96$ ) (Figure 3). Kaï not only significantly chose the inattentive caretaker $(N=42, \mathrm{k}=31, p<0.01)$, he also looked at her for significantly longer before choosing (Figure 3$)(\mathrm{W}=429, p<0.01)$. Santo $(N=42, \mathrm{k}=37, p<0.001)$, Smack $(N=42, \mathrm{k}=$ $37, p<0.001)$, and Gonzo $(N=42, \mathrm{k}=35, p<0.001)$ showed a side preference (Figure 3$)$ (right, left, and right, respectively). 


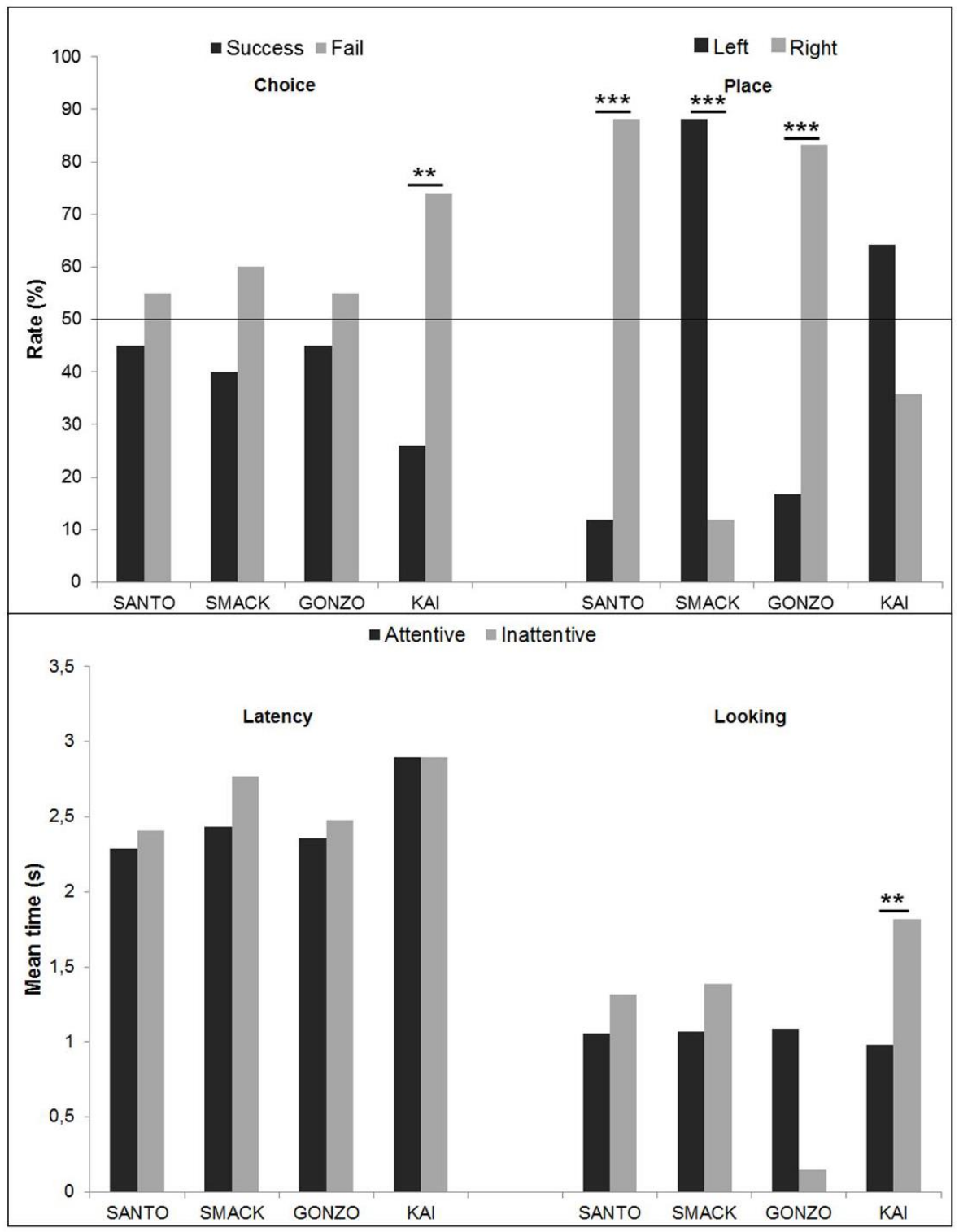

Figure 3. Test 2.1: head orientation. For each sea lion, Success / Failure rate and place (top) and mean time (s) of the response time (latency) and duration (s) of looking at the caretakers (down) during experiment 2.1. The line shows the random level with $50 \%$. $*=\mathrm{p}<0.05 ; * *=\mathrm{p}<0.01 ; * * *=\mathrm{p}<0.001$

\section{Part 2: Face forward/body forward vs. face turned/body forward}

For this test, the attentive caretaker had her body and head facing the sea lion, while the inattentive caretaker had her body oriented towards the animal but her head turned away. The subjects received a variable number of trials (Santo: 37; Smack: 43; Gonzo: 46; and Kaï: 44).

Results. The four sea lions failed this test $(N=171, \mathrm{k}=87, p=0.82)$, and did not show any difference in their latencies to choose a caretaker ( $\mathrm{W}=3304, p=0.99)$ (Figure 4). Only Santo looked longer at the attentive caretaker versus the inattentive one before choosing ( $\mathrm{W}=885, p<0.05)$. All four subjects showed a significant side bias in this experiment (Test 2.1): Santo and Gonzo went to the left ( $N$ $=37,46, \mathrm{k}=36,35, p<0.001$, respectively), while Smack and Kaï went to the right $(N=43,44, \mathrm{k}=39$, $30, p<0.001,0.05$, respectively). 


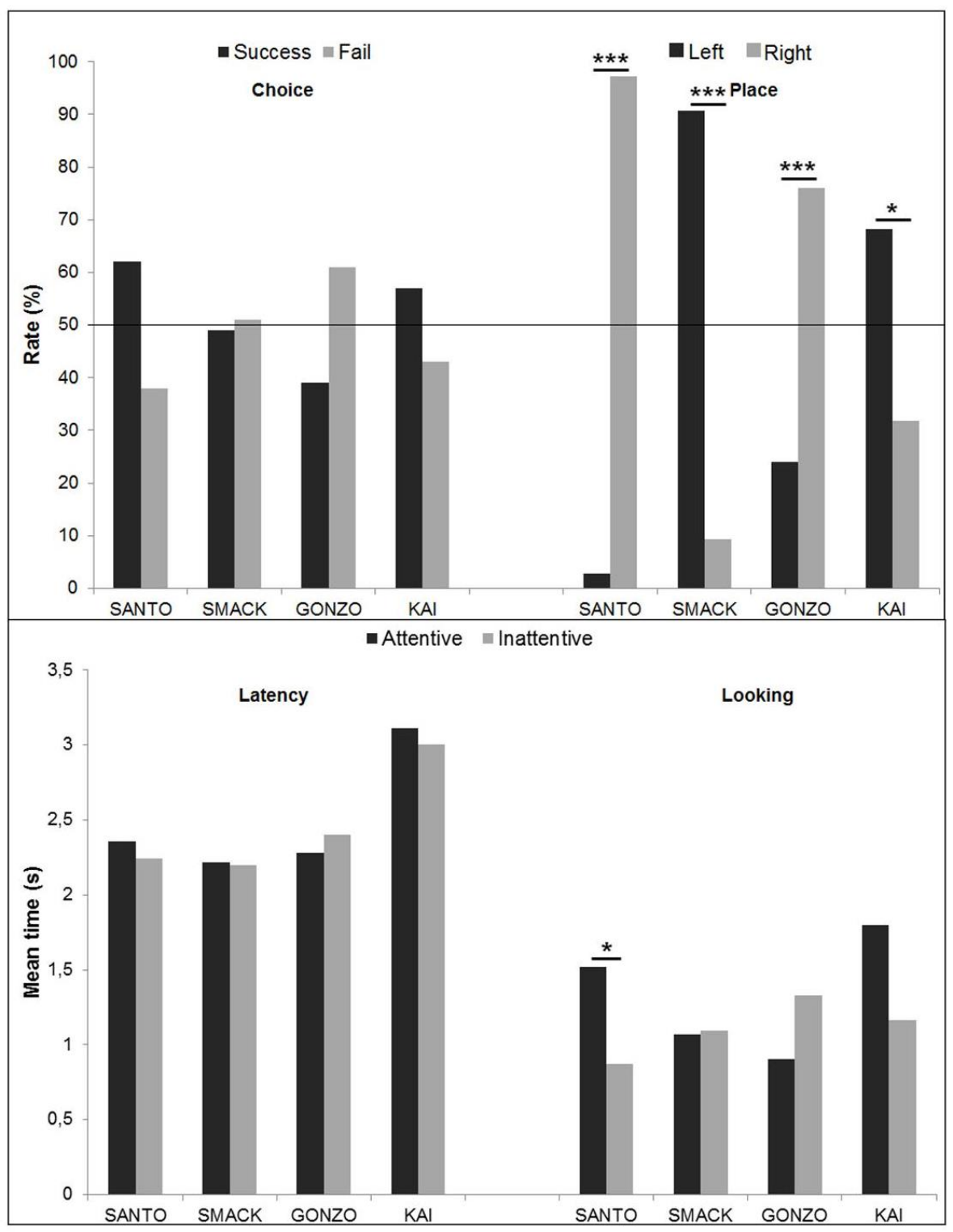

Figure 4. Test 2.2: head orientation. For each sea lion, Success / Failure rate and place (top) and mean time (s) of the response time (latency) and duration (s) of looking at the caretakers (down) during experiment 2.2. The line shows the random level with $50 \%$. $* \mathrm{p}<0.05 ; * *=\mathrm{p}<0.01 ; * * *=\mathrm{p}<0.001$

\section{Experiment 3: Eye visibility}

\section{Eyes open vs. sunglasses}

Shaping phase 2 and procedure. Before experiment 3 , a second shaping phase introduced a new posture to the animals: caretakers knelt down in front of the sea lions and looked at them. This posture allowed the subjects to see their caretakers' eyes (Figure 1). The attentive caretaker wore sunglasses without tinted lens, whereas the inattentive caretaker wore the normal, dark sunglasses. The subjects received 42 trials.

Results. The four sea lions failed this test $(N=168, \mathrm{k}=90, p=0.39)$, and their latencies to choose between the two trainers did not show any significant difference $(\mathrm{W}=3375.5, p=0.76)$. Nor did 
they look longer at the attentive versus inattentive caretaker before choosing ( $\mathrm{W}=14505.5, p=0.28)$ (Figure 5). They again all showed a particular side bias, Santo and Gonzo choosing right $(N=42, \mathrm{k}=38$, $37, p<0.001$, respectively) and Smack and Kaï choosing left $(N=42,50, \mathrm{k}=37,40, p<0.001$, respectively).

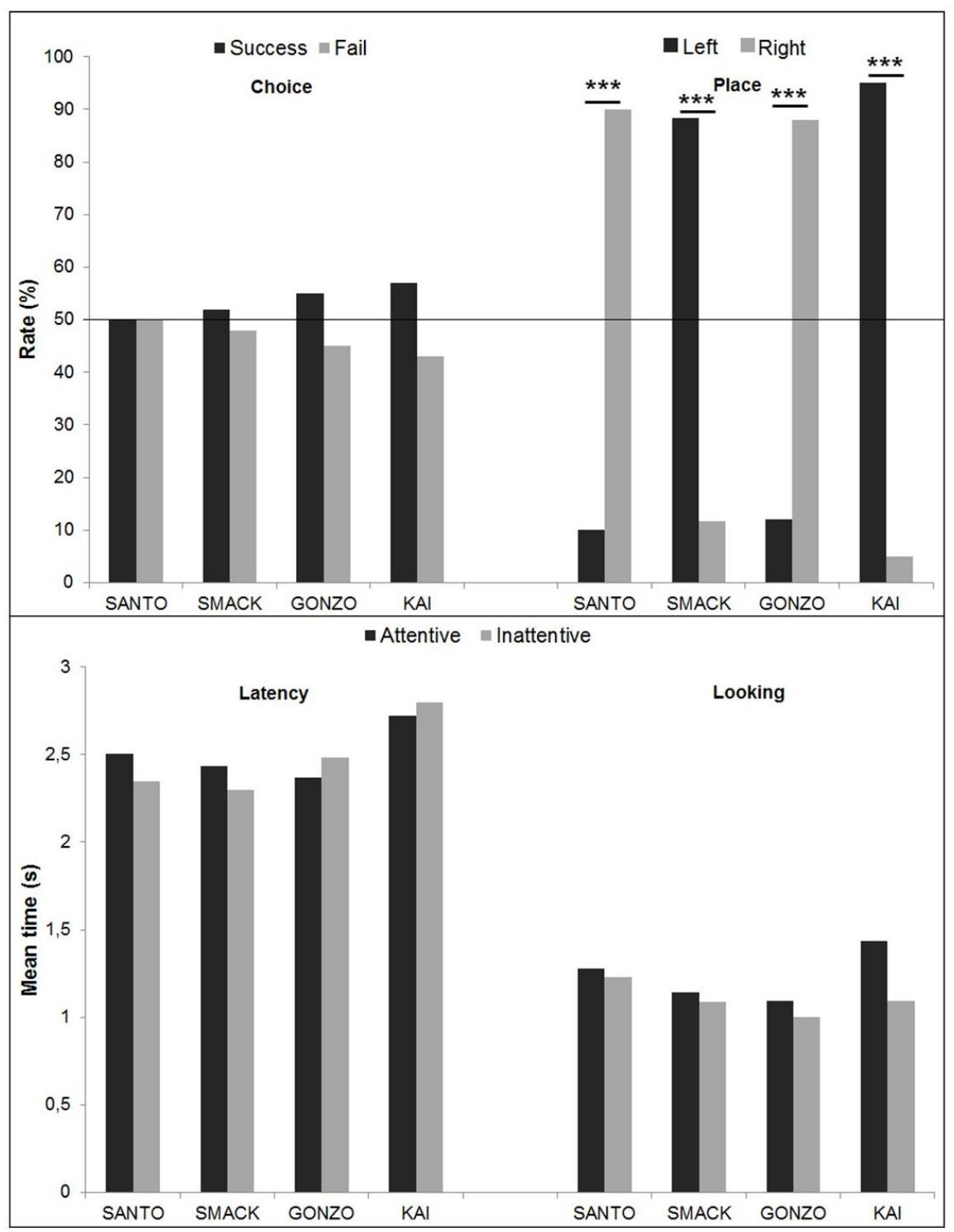

Figure 5. Test 3: eye visibility. For each sea lion, Success / Failure rate and place (top) and mean time (s) of the response time (latency) and duration (s) of looking at the caretakers (down) during experiment 3. The line shows the random level with $50 \%$. $*=\mathrm{p}<0.05 ; * *=\mathrm{p}<0.01 ; * * *=\mathrm{p}<0.001$

\section{Discussion}

The four tested sea lions preferentially chose an attentive caretaker who had her body turned towards them, but they did not seem to be able to discriminate attentional cues when the caretakers took a more ambiguous posture. In the latter case, they demonstrated significant side biases by "choosing a particular side." 
Before discussing each test, we would like to mention that of course the four sea lions have been exposed to their caretakers' gestures: they were not naïve. However, they have never been subjects in experiments testing their theory of mind and they have never seen their caretakers wearing sunglasses. Of course, one could think that some situations are more encountered by the sea lions that others throughout their training history (e.g., body forward vs back turned) and their choice could be influenced by neophobia. However at this state, this would be pure speculation since no scientific data is available. More information on the sea lions' daily life and history of exposure to humans' gestures are needed to answer this point. However, we were interested in conducting situated cognitive experiments by testing the four subjects' sensibility to their caretakers' attentional states in situations they have never experienced before but in contexts they know (i.e., familiar humans, known location, test occurring during regular training session and mixed with known exercises, etc).

In the facing versus back turned test the sea lions preferentially chose the attentive caretaker, recalling results reported in dogs (Virányi et al., 2004) and horses (Proops \& Mc Comb, 2010). The subjects seemed to base their choice on their experience of this human body orientation being correlated with ability to give food. Moreover, previous studies showed that dogs beg for food more often when a human is facing them versus facing away (Miklósi et al., unpublished data, as cited in Bräuer et al., 2004; Kaminski, Call, \& Tomasello, 2004). Bottlenose dolphins (Tursiops truncatus), South African fur seals (Arctocephalus pusillus) and grey seal (Halichoerus grypus) show similar results in a similar task (Schudin et al., 2001, as cited in Kaminski et al., 2005; Scheumann \& Call, 2004; Shapiro et al., 2003). Interestingly, some authors have explained the good performance of dogs in terms of their long history of co-habitation with humans and selective breeding (Call, 2001). However, wolves (Canis lupus), reared and socialized by humans, were also able to understand some attentional states of humans (Udell et al., 2011). Domestication is therefore not a prerequisite for understanding human attentional states; our results are in agreement with this. However, unlike in similar studies with horses (Proops \& McComb, 2010) and dogs (Gásci et al., 2004), three sea lions did not take more time to choose the attentive caretaker, even although all four subjects looked longer at the attentive caretaker before making their choice. One individual (Smack) showed a longer latency when choosing the attentive caretaker compared to the inattentive one, and he also looked longer at the attentive trainer. Similar results were found with capuchin monkeys (Cebus apella) (Hattori, Kurosima, \& Fujita, 2007): they looked longer at the experimenter looking at them vs. looking at the ceiling. Conceivably, Smack was looking for the "right" caretaker, but his inability to find the attentive caretaker might have been due to some caretakers' ambiguous and/or inadvertent cues or some trouble discriminating the two cues.

When both caretakers' bodies were oriented towards the subject but one was looking away, and when one was fully oriented towards the subject while the other's body was oriented away but her head faced the subjects, the attentive trainer was not preferentially selected or looked at for longer. The sea lions did not appear to notice or understand the importance of the head orientation. Bottlenose dolphins showed similar results, paying more attention to the body than the head of their caretakers (Tomonaga, Uwano, Ogura, \& Saito, 2010). Bonobos (Pan paniscus), gorillas and orangutans understand human attentive states using head cues (Bania \& Stromberg, 2013; Tempelman et al., 2011). Moreover, these primates selected humans who were in the best position to give them food (e.g., body turned but hand towards the subject) (Tempelman et al., 2011). California sea lions, like some great apes (Kaminski et al., 2004), appeared to process cues from the human body in hierarchical fashion. For our subjects, the body might be a more important cue than the head, meaning that the inattentive caretaker could therefore be a good choice for them. Interestingly, in test 2.1, Kaï looked longer at the inattentive caretaker with her body oriented towards him than the attentive before choosing, and he did not choose a particular side, indicating that his choice was mainly based on the caretaker's body orientation.

The sea lions' size should be taken into consideration when examining the present results. These animals are between $50 \mathrm{~cm}$ and $1 \mathrm{~m}$ tall (from head to ground), while the caretakers are about 1.70 to 1.75 $\mathrm{m}$ tall. When moving forward, sea lions do not look up beyond $1.20 \mathrm{~m}$, so they only see the caretakers' abdominal belt, not the head. Moreover, sea lions do not only "walk"; they can slide along or combine these two methods. According to Emery (2000), when the head is not accessible for an animal, body cues 
are used to discriminate attentive states. Replicating the set of experiments 2.1 and 2.2 with trainers kneeling down might bring different results. In order to make sure the trainers' head and eyes were visually accessible in test 3 , the caretakers knelt down. When confronted with eyes accessible versus not accessible conditions, the four sea lions again failed to discriminate; this suggest that, contrary to horses, dogs and baboons (Papio papio) (Bräuer et al., 2004; Proops \& McComb, 2010; Soproni et al., 2001), sea lions may not be sensitive to human gaze. As the subjects previously failed to appreciate that the head cue was a more salient cue than body orientation, this result is not surprising. Several factors could explain these results. First, eyes may simply be a non-pertinent stimulus for the sea lions. Like orangutans (Gretscher, Haun, Liebal, \& Kaminski, 2012) but unlike chimpanzees (Bräuer, Call, \& Tomasello, 2007), sea lions might need more salient cues to infer if someone is looking at them or not. Their limited understanding of what humans can and cannot see might mean that they did not understand that the attentive caretaker was paying attention to them (Emery, 2000). Alternatively, they might not have understood that the sunglasses blocked the caretaker gaze; in contrast dogs show a better understanding of humans' visual perception and that an opaque barrier will block human's experience of seeing an object (Bräuer et al., 2004).

Our data suggest that from test 2.1 the subject did not understand what was required of them and they instead adopt an alternative strategy, namely choosing a particular side. Considering their latencies and their looking behavior, their side choices became increasingly stronger. Wells et al. (2006) showed that California sea lions have a different lateralized swimming pattern according to gender: males swim preferentially in a clockwise direction whereas females swim counterclockwise. The possible lateralized behaviors of the four sea lions could have influenced the results obtained here. In other words, they might have adopted a behavior based on some stimuli (a side) instead of the caretakers' posture, as did dogs (Kaminski et al., 2009).

Our results do not support the idea that young sea lions possess a concept of "social attention". According to Chance (1967; as cited in Emery, 2000), each individual of a social group gives and receives attention according to its social position (dominant/subordinate). Studies of captive sea lions have shown hierarchical relationships among individuals of the same sex (Hanggi \& Schusterman, 1990; Schusterman, 1968). Our subjects were young and of a similar ages, and as yet we have no information about their relationships. Another set of experiments should be conducted to bring more information on that topic.

Although, the sea lions did not seem to attend to physical signs of caretaker's attentional states, several parameters might have compromised the subjects' understanding of the situation. First, the layout of the test arena could have influenced our results (Hare, 2001); studies shown that social tensions are diminished in large arenas. Second, using an opaque barrier (Braüer et al., 2004) instead of sunglasses might make it easier for the subjects to infer the humans' perspective. Third, more detailed analysis of the sea lions' behaviors might clarify what they understand of the test. For instance, caretakers reported that the subjects sometimes tried to get their attention by touching their hands. Similar behaviors were described in horses (Proops \& McComb, 2010) and chimpanzees (Theall \& Povinelli, 1999). Finally, delivery of food rewards by the attentive caretaker might facilitate the task. In other studies (Bräuer et al., 2004; 2007; Proops \& McComb, 2010; Tempelman et al., 2011; Udell et al., 2011), experimenters used food as a primary reward.

To conclude, our results call for testing California sea lions in other experimental situations, and more naturalistic ones. According to Gásci et al. (2004), gazing as a sign of attention is a specifically human trait, but ignorance of gaze cues by other species does not mean complete ignorance of attention. Our sea lions subjects were born in captivity and raised by humans, a situation that is particularly useful for investigating interspecific communication.

\section{Acknowledgements}

The authors would like to thank dolphinarium curator Birgitta Mercera and the following Sea lion trainers: Caroline Lévy, Stéphane Lecki, Déborah Mallet, Bastien Servières, Daphné Vergon, Juana 
Serrano, Julie Lovato, Lauranne Torres and Fleur Besnoiy who alternatively were experimenters A, B and $\mathrm{C}$ or took care of the non-tested sea lions while the experiment was conducted. The authors are indebted to James Anderson for his careful review. They also would like to acknowledge the contributions made by two $\mathrm{ABC}$ anonymous reviewers.

\section{References}

Bania, A. E., \& Stromberg, E. E. (2013). The effect of body orientation on judgements of visual attention in western lowland gorillas (Gorilla gorilla gorilla). Journal of Comparative Psychology, 127, 82-90.

Baron-Cohen S. (1994). How to build a baby that can read minds: Cognitive mechanisms in mindreading. Cahier de Psychology Cognitive, 13, 13-52.

Bräuer, J., Call, J., \& Tomasello, M. (2004). Visual perspective taking in dogs (Canis familiaris) in the presence of barriers. Animal Behaviour Science, 88, 299-317.

Bräuer, J., Call, J., \& Tomasello, M., (2007). Chimpanzees really know what others can see in a competitive situation. Animal Cognition, 10, 439-448. doi: 10.1007/s10071-007-0088-1

Buttelman, D., Carpenter, M., Call, J., \& Tomasello, M. (2007). Enculturated chimpanzees imitate rationally. Developmental Science, 10, F31-F38. doi: 10.1111/j.1467-7687.2007.00630.x

Call, J. (2001). Chimpanzee social cognition. TRENDS in Cognitive Sciences, 5, 388-393.

Emery, N. J. (2000). The eyes have it: The neuroethology, function and evolution of social gaze. Neuroscience and Behavioral Reviews, 24, 581-604.

Gásci, M., Miklósi, Á., Varga, O., Topál, J., \& Csányi, V. (2004). Are readers of our face readers of our minds? Dogs (Canis familiaris) show situation-dependent recognition of human's attention. Animal Cognition, 7 , 144-153. doi: 10/1007/s10071-003-0205-8

Giret, N., Miklósi, Á., Kreutzer, M., \& Bovet, D. (2009). Use of experimenter-given cues by African gray parrots (Psittacus erithacus). Animal Cognition, 12, 113-121.

Gretscher, H., Haun, D. B. M., Liebal, K., \& Kaminski, J. (2012). Orang-utan rely on orientation cues and egocentric rules when judging other's perspectives in a competitive food task. Animal Behaviour, 84, 323331.

Hare, B. (2001). Can competitive paradigms increase the validity of experiments on primate social cognition?. Animal Cognition, 4, 269-280.

Hanggi, E.B. \& Schusterman R.J. (1990). Kin recognition in captive California sea lions (Zalophus californianus). Journal of Comparative Psychology, 104.4, 368.

Hattori, Y., Kurosima, H., \& Fujita, K. (2007). I know you are not looking at me: Capuchin monkeys' (Cebus apella) sensitivity to human attentional states. Animal Cognition, 10, 141-148. doi: 10.1007/s10071-0060049-0

Kaminski, J., Bräuer, J., Call, J., \& Tomasello, M. (2009). Domestic dogs are sensitive to a human's perspective. Behaviour, 146, 979-998. doi: 10.1163/156853908X395530

Kaminski, J., Call, J., \& Tomasello, M. (2004). Body orientation and face orientation: Two factors controlling apes' begging behavior from humans. Animal Cognition, 7, 216-223. doi: 10.1007/s10071-004-0214-2

Kaminski, J., Riedel, J., Call, J., \& Tomasello, M. (2005). Domestic goats (Capra hircus) follow gaze direction and use social cues in an object choice task, Animal Behaviour, 69, 11-18. doi:10.1016/j.anbehav.2004.05.008

Miklósi, Á., Polgárdi, R., Topál, J., \& Csányi, V. (1998). Use of experimenter given cues in dogs. Animal Cognition, $1,113-121$.

Péron, F., Chardard, C., Nagle, L., \& Bovet, D. (2011). Do African gray parrots (Psittacus erithacus) know what a human experimenter does and does not see?. Behavioural Processes, 87, 237-240.

Premack, D., \& Woodruff. G. (1978). Does the chimpanzee have a theory of mind?. Behavioral and Brain Sciences, 4, 515-526.

Proops, L., \& McComb, K. (2010). Attributing attention: The use of human given cues by domestic horses (Equus caballus). Animal Cognition, 13, 197-205. doi: 10.1007s/1007-009-0257-5

Riedman, M. (1990). The pinnipeds: Seals, sea lions, and walruses (No. 12). Los Angeles: University of California Press.

Santos, L. R., \& Hauser, M. D. (1999). How monkeys see the eyes: Cotton-top tamarins' reaction to changes in visual attention and action, Animal Cognition, 2, 131-139.Scheumann, M., \& Call, J. (2004). The use of experimenter-given cues by South African fur seals (Arctocephalus pusillus). Animal Cognition, 7, 224-230. doi: $10.1007 / \mathrm{s} 10071-004-0216-0$ 
Schusterman, R. J. (1968). Experimental studies of pinniped behavior. In R. J. Harrison, R. C. Hubbard, R. S. Peterson, C. e. Rice \& R. J. Schusterman (Eds.), The behavior and physiology of pinnipeds. New York: Appleton-Century-Crofts.

Schusterman, R. J. (1969). Aerial and underwater visual acuity in the California sea lion as a function of luminance, Naval Undersea Res. And Develop. Center Final Rep, June 5, 1969, Contract N00123-69-C-0208

Shapiro, A. D., Janik, V. M., \& Slater, P. J. B. (2003). A gray seal's (Halichoerus grypus) responses to experimenter given pointing and directional cues. Journal of Comparative Psychology, 117, 122-126.

Soproni, K., Miklósi, Á., Topál, J., \& Csányi, V. (2001). Comprehension of human communicative signs in pet dogs (Canis familiaris). Journal of Comparative Psychology, 115, 122-126.

Tempelmann, S., Kaminski, J., \& Liebal, K. (2011). Focus on the essential: All great apes know when others are being attentive. Animal Cognition, 14, 433-439. doi: 10.1007/s10071-011-0378-5

Theall, L. A., \& Povinelli, D. J. (1999). Do chimpanzees tailor their gestural signals to fit the attentional states of others?. Animal Cognition, 2, 207-214.

Tomonaga, M., Uwano, Y., Ogura, S., \& Saito, T. (2010). Bottlenose dolphins' (Tursiops truncatus) theory of mind demonstrated by responses to their trainers' attentional states. International Journal of Psychology, 23, 386400.

Udell, M. A. R., Dorey, N. R., \& Wynne, C. D. L. (2010). What did domestication do to dogs? A new account of dogs' sensitivity to human actions. Biological Reviews, 85, 327-345. doi: 10.1111/j.1469-185X.2009.00104.X

Udell, M. A. R., Dorey, N. R., \& Wynne, C. D. L. (2011). Can your dog read your mind? Understanding the causes of canine perspective taking. Learning \& Behavior, 39.4, 289-302. doi: 10.3758/s13420-011-0034-6

Virányi, Z., Topál, J., Gásci, M., Miklósi, Á., \& Csányi, V. (2004). Dogs respond appropriately to cues of humans' attentional focus. Behavioural Processes, 66, 161-172.

Wells, D. L., Irwin, R. M., \& Hepper, P. G. (2006). Lateralised swimming behaviour in the California sea lion. Behavioural Processes, 73, 121-123.

Xitco, M. J. Jr., Gory, J. D., \& Kuczaj, S. A. (2004). Dolphin pointing is linked to the attentional behavior of a receiver. Animal Cognition, 7, 231-238. 